\title{
The Protective Effect of Cell Wall and Cytoplasmic Fraction of Selenium Enriched Yeast on 1, 2-Dimethylhydrazine-induced Damage in Liver
}

\author{
Mitra Dadrass ${ }^{{ }^{*}}$, Vahid Nejati ${ }^{1}$, Amir Tukmechi ${ }^{2}$, Rahim Hobbenaghi ${ }^{3}$ \\ ${ }^{1}$ Department of Biology, Faculty of Science, Urmia University, Urima, Iran. \\ ${ }^{2}$ Department of Pathobiology and Quality Control, Artemia and Aquatic Research Institute, Urmia University, Urima, Iran. \\ ${ }^{3}$ Department of Pathobiology, Faculty of Veterinary Medicine, Urmia University, Urima, Iran.
}

Received: 1 Dec 2013

Revised : 10 Jan 2014

Accepted: 20 Jan 2014

Corresponding Authors:

Mitra Dadrass

Department of biology, Faculty of

Science, Urmia University, University

Boulevard (sero Road), Urmia, West

Azarbaijan.

Phone: +98-9141406586

E-mail: mitra_dadrass@yahoo.com

\begin{abstract}
Background: 1, 2-Dimethylhydrazine (DMH) enhances lipid peroxidation rate by tumor mitochondria than normal tissue counterpart and causes many disorders in antioxidant system in liver. It also increases the level of enzymes that metabolize toxin in liver and colon. The aim of this study was to evaluate the alteration of liver and its enzymes after DMH injection and evaluate protective effect of cell wall and cytoplasmic fractions of Saccharomyces cereviseae enriched with selenium (Se) on these tissues.

Materials and Methods: Forty eight female rats were prepared and acclimatized to the laboratory conditions for two weeks, and all animals received 1,2-dimethyl hydrazine chloride $(40 \mathrm{mg} / \mathrm{kg}$ body weight) twice a week for 4 weeks except healthy control. At first colon carcinoma (aberrant crypt foci) confirmed by light microscope. Then the changes resulting from injection of DMH on liver of animals in initial and advanced stages of colon cancer were examined. In addition, the protective effect of cell wall and cytoplasmic fractions of Selenium-enriched $S$. cerevisiae were investigated in two phases. First phase in initial stage and second phase in advanced stage of colon cancer were performed respectively. Forty weeks following the first DMH injection, all survived animals were sacrificed. Then, colon and liver removed and exsanguinated by heart puncture. For measuring the levels of enzymes (AST, ALT, and ALP), a commercial kit (Parsazmoon, Iran) and an autoanalyzer (BT 3000 Pluse, Italy) were used.

Results: The results showed that subcutaneous injection of DMH increased the ALT, AST, and ALP levels up to 78.5, 161.38, and 275.88 U/L compared to the control, respectively. Moreover, statistical analysis in both phases of experiment revealed that the enzyme levels were decreased in the treated groups in comparison with the DMH-injected group, while the levels of these enzymes were lower in the control group.

Conclusion: It should be concluded that administration of cell wall and cytoplasmic fraction prepared from Se-enriched S. cerevisiae could reduce the tissue damages in the livers DMH-injected rats. This beneficial effect would warrant further study on the clinical application of Se-enriched yeast.
\end{abstract}

Keywords: Dimethyl hydrazine; Liver enzymes; AST; ALT; ALP; Saccharomyces cerevisiae, Selenium; Colon cancer

Please cite this article as: Dadrass M, Nejati V, Tukmechi A, Hobbenaghi R. The Protective Effect of Cell Wall and Cytoplasmic Fraction of Selenium Enriched Yeast on 1, 2-Dimethylhydrazine-induced Damage in Liver. Res Mol Med. 2014; 2 (1): 39-45.

\section{Introduction}

1, 2-dimethylhydrazine has been widely used to induce colon cancer in experimental models becauseof the similar pathology between this model and human diseases (1). DMH is a colon specific carcinogen, an alkylating agent that believed to form active intermediates including azoxymethane (AOM) and 
methylazoxymethanol (MAM) in liver. They could be transported into the colon through bile (2). Under physiological conditions, MAM is unstable and breaks down to form the strong alkylating agents, methyldiazonium hydroxide, formaldehyde, and also it is found that the MAM glycoside (cycasin) is a potent carcinogen (3). DMH enhances the lipid peroxidation rate by tumor mitochondria 8 - to 10 -fold more than normal tissue counterparts (4) and causes many disorders in antioxidant system in liver and also increases the activity of enzymes that metabolize toxin in liver and colon (5).

Table 1. Level of liver enzymes in the first phase of treatment. Data are present as the means \pm SE. Values not sharing common superscript letter (a-d) differ.

\begin{tabular}{|c|c|c|c|}
\hline Parameters groups & Level of ALT (U/L) & Level of AST (U/L) & Level of ALP (U/L) \\
\hline Cancer control & $78.5 \pm 0.50^{\text {a }}$ & $161.38 \pm 0.37^{\text {a }}$ & $275.88 \pm 0.87^{a}$ \\
\hline Control & $63.5 \pm 0.51^{b}$ & $125.30 \pm 0.30^{c}$ & $218.65 \pm 0.65^{b}$ \\
\hline Selenium & $63.5 \pm 0.50^{\mathrm{b}}$ & $145.50 \pm 0.51^{\mathrm{b}}$ & $268.44 \pm 0.55^{a}$ \\
\hline Yeast cell wall & $71.62 \pm 0.37^{\text {a }}$ & $140.50 \pm 0.50^{\mathrm{b}}$ & $262.0 \pm 1.0^{\mathrm{a}}$ \\
\hline Yeast cytoplasmic fraction & $57.63 \pm 0.36^{b}$ & $144.50 \pm 0.52^{b}$ & $161.67 \pm 0.67^{\mathrm{d}}$ \\
\hline Yeast cell wall enriched with selenium & $50.62 \pm 0.37^{\mathrm{b}}$ & $124.38 \pm 0.38^{\mathrm{c}}$ & $182.72 \pm 0.72^{\mathrm{c}}$ \\
\hline Yeast cytoplasmic fraction enriched with selenium & $56.61 \pm 0.38^{\mathrm{b}}$ & $140.75 \pm 0.25^{\mathrm{b}}$ & $247.0 \pm 1.0^{\mathrm{a}}$ \\
\hline
\end{tabular}

Significantly from each other at $\mathrm{P}<0.05$ in each column (ANOVA followed by HSD.

Probiotics can be defined as nonpathogenic microorganisms that exert a positive effect on the health or physiology of the host following ingestion. They consist of either yeast or bacteria especially lactic acid bacteria. Their fate in the gastrointestinal tract and effects differ among strains. Probiotics are thought to modulate the direct or indirect effects on endogenous flora or immune system (6). Probiotics play an important role in prevention of disease by reducing fecal enzymes and bile salt concentration and by decreasing absorption of harmful carcinogens causing colon cancer. Probiotics can also inhibit absorption of toxin and consequently may help to cure and prevent liver diseases (7). Selenium (Se) is considered as an essential element for humans, animals, and fish. This element is the main component of glutathione peroxidase which protects cells and membranes against oxidative damages caused by free radicals (8). Saccharomyces, yeast fungi and unicellular eukaryotes, have been used as a model for research in various fields of science, medicine and biotechnology. Saccharomyces have two species included Saccharomyces Boulardii and Saccharomyces cerevisiae that are considered as probiotics. Yeast cell wall is a non-specific stimulator of the immune system of both humans and animals. Numerous scientific studies have shown that when ingesting orally, yeast beta-glucan -a constituent of yeast cell wall- can stimulate the cells of the immune system (macrophages) and help to overcome bacterial infections. The cell wall and cytoplasmic fractions of $S$. cerevisiae have anticancer activity and inhibit the growth of K562 cells in vitro system (9). The levels of serum liver enzymes are used to evaluate liver function; increases in level of these enzymes are linked to hepatic lesions or hepatocytes damage (10). Consequently, hepatic lesions or occurrence of necrosis causing to release these enzymes in blood circulation (11). Thus, according to previous studies i the field of probiotics and selenium, the purpose of this study was to investigate the alteration of liver and its enzymes following $\mathrm{DMH}$ injection and evaluate protective effect of cell wall and cytoplasmic fractions of $S$. cereviseae enriched with selenium on these tissues, as well.

\section{Materials and Methods}

Animal and chemicals preparation

All animals (Wistar rats with 150-200g initial body weight) were provided by the animal house of the Faculty of Science, the University of Urmia. All materials including 1, 2-dimethyl hydrazine chloride, yeast extract, D-glucose, $\mathrm{K}_{2} \mathrm{HPO} 4$ and sodium selenite were purchased from Sigma-Aldrich (US). Also $S$. cerevisiae was provided by the Iran industrial collections center of fungi and bacteria (PTCC5269).

\section{Yeast culture and enrichment}

For yeast culturing a medium was designed containing yeast extract $(\% 2)$, D-glucose $(\% 5)$ and $\mathrm{K}_{2} \mathrm{HPO} 4$ (\%1), (2). Yeast enrichment was done according to the method of Wang et al. (12) and Yin et al. (13). Briefly, $10 \mathrm{mg}$ yeast powder was added to $90 \mathrm{ml}$ of the mentioned medium and incubated at $27.4{ }^{\circ} \mathrm{C}$ for 12 hours. Then $90 \mu \mathrm{l}$ sodium selenite (10 $\mathrm{mg} / \mathrm{ml}$ ) was added to the medium and incubation was continued for 48 hours. After that, the medium was centrifuged at $3000 \mathrm{rpm}$ for 15 minutes. To remove 
additional selenium, the pellet was washed twice with sterile normal saline. In this study $S$. cerevisiae cultured at the same condition without enrichment by selenium.

Table 2. Levels of liver enzymes in the second phase of treatment data are present as the means \pm SE. Values not sharing common superscript letter (a-d) differ.

Significantly from each other at $\mathrm{P}<0.05$ in each column (ANOVA followed by HSD).

\begin{tabular}{|c|c|c|c|}
\hline Parameters groups & Level of ALT (U/L) & Level of AST (U/L) & Level of ALP (U/L) \\
\hline Cancer control & $78.5 \pm 0.50^{a}$ & $161.38 \pm 0.37^{\mathrm{a}}$ & $275.88 \pm 0.87$ a \\
\hline Control & $63.5 \pm 0.51^{b}$ & $125.30 \pm 0.30^{\mathrm{c}}$ & $218.65 \pm 0.65 \mathrm{~d}$ \\
\hline Selenium & $57.5 \pm 0.52 \mathrm{~b}$ & $145.50 \pm 0.51^{b}$ & $259.88 \pm 0.87 \quad b$ \\
\hline Yeast cytoplasmic fraction & $73.5 \pm 0.50^{\mathrm{a}}$ & $153.50 \pm 0.50^{b}$ & $254.0 \pm 1.0^{b}$ \\
\hline Yeast cell wall enriched with selenium & $56.5 \pm 0.50^{b}$ & $124.44 \pm 0.44^{\mathrm{c}}$ & $221.0 \pm 0.95^{\mathrm{c}}$ \\
\hline Yeast cytoplasmic fraction enriched with selenium & $72.5 \pm 0.51^{\text {a }}$ & $144.50 \pm 0.52 \mathrm{~b}$ & $249.0 \pm 0.93 \quad b$ \\
\hline
\end{tabular}

Separation of cell wall and cytoplasmic fraction of Yeast and enriched Yeast with selenium

To separate the cell wall and cytoplasmic fraction of Yeast and enriched Yeast with selenium, freeze-thaw method was used. Phosphate buffer saline was added to the washed pellet of $S$. cerevisiae prepared by the method of Wang et al. (12) and Yin et al. (13). Later on selenium-enriched yeast and yeast without enrichment were dipped into liquid nitrogen (-196 ${ }^{\circ} \mathrm{C}$ ) for several times. After 5 minutes, the yeasts were located in water bath at $37{ }^{\circ} \mathrm{C}$. Finally, the samples were centrifuged with $12000 \mathrm{rpm}$ for 30 minutes, the supernatant was collected as cytoplasmic fraction and the pellet was used as the yeast cell wall. Protein content of obtained cell wall and cytoplasmic fraction were determined by the Bradford method (14), and after sterilizing by a UV lamp, both components were stored at $20^{\circ} \mathrm{C}$ until use.

\section{Experiment Design}

Forty eight animals with $150-200 \mathrm{~g}$ initial body weight which acclimatized to the laboratory conditions for one week and maintained at 12 hours dark-light cycles, 23-25 ${ }^{\circ} \mathrm{C}$ and 50 percent of humidity during experimental period. All animals except the control received subcutaneously 1, 2dimethylhydrazine chloride $40 \mathrm{mg} / \mathrm{kg}$ body weight (dissolved in EDTA $0.1 \mathrm{mM}$ and $\mathrm{pH}=6.5$ ), twice a week for 4 weeks. For investigating the changes due to injection of DMH on the liver of animals in initial and advanced stages of colon cancer, and also assessing the protective effect of our experimental treatment on these damages, the experiment was conducted in two phases. The first phase that was considered as investigating the protective effect of our experimental treatment on the liver in initial stages of colon cancer, contained seven treated groups such as control, DMH (40 $\mathrm{mg} / \mathrm{kg}$ body weight), DMH with Se (4 mg/l orally), DMH with Se-enriched yeast cell wall $(2000 \mu \mathrm{g} / \mathrm{ml}$ i.p. $), \mathrm{DMH}$ with Se-enriched yeast cytoplasmic fraction $(2000$ $\mu \mathrm{g} / \mathrm{ml}$ i.p.), DMH with yeast cell wall $(2000 \mu \mathrm{g} / \mathrm{ml}$ i.p.) and $\mathrm{DMH}$ with yeast cytoplasmic fractions (2000 $\mu \mathrm{g} / \mathrm{ml}$ i.p.) without enrichment, separately (Figure 1). The second phase was considered to investigate the protective effect of our experimental treatment on the liver in advanced stages of colon cancer and contained seven treated groups such as control, DMH (40 mg/kg body weight), DMH with $\mathrm{Se}(4 \mathrm{mg} / \mathrm{l}$ orally), DMH with Se-enriched yeast cell wall $(2000 \mu \mathrm{g} / \mathrm{ml}$ i.p.), DMH with Se-enriched yeast cytoplasmic fraction $(2000 \mu \mathrm{g} / \mathrm{ml}$ i.p.), DMH with yeast cell wall $(2000 \mu \mathrm{g} / \mathrm{ml}$ i.p.) and DMH with yeast cytoplasmic fractions $(2000 \mu \mathrm{g} / \mathrm{ml}$ i.p.) without enrichment, separately (Figure 2). After 18 weeks of first DMH injection, one or two preneoplastic lesions of colon cancer like as aberrant crypt foci (ACF), dysplastic epithelium, were observed based on the method of Bird and Good (15) that showed the initiation step of carcinogenesis (Figure 4). 32 week after the first DMH injection by observation multiplicity of ACF in colon from a rat treated with $\mathrm{DMH}$, the second phase was run like as the first phase and animals received agents twice a week for 4 weeks, intraperitoneally. In this study, colon and liver damages were assayed by preparation of tissue sections and microscopic examination.

\section{Identification of lesions of colon or ACFs}

The colon was detached, washed with $0.9 \%$ saline, opened from cecum to anus, divided into three segments, and fixed flat between two pieces of filter paper in $10 \%$ buffered formalin. Microscopic slides were placed on top of the filter paper to ensure that 
the tissue remained flat during fixation. After $24 \mathrm{~h}$ in buffered formalin, the colon specimens were stained with $0.2 \%$ methylene blue as described by Bird and Good, 2000 (15).

Then, it was placed on a microscopic slide and observed under a light microscope. Aberrant crypts were distinguished from the surrounding normal crypts by their increased size, significantly increased distance from laminae to basal surface of cells, and the easily discernible pericryptal zone.

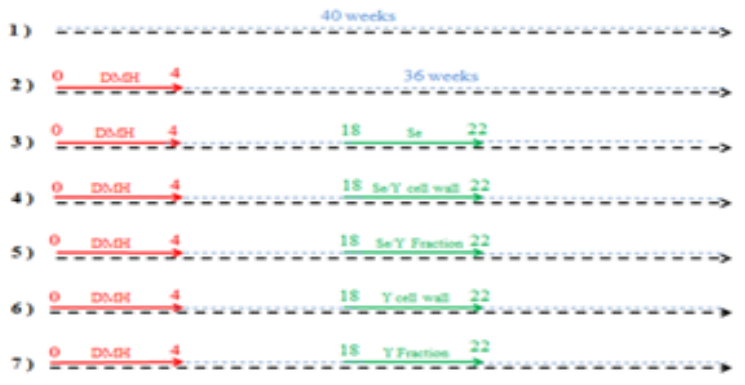

Figure 1. Experimental protocol in first phase. All animals except the control received 1,2-dimethylhydrazine chloride $40 \mathrm{mg} / \mathrm{kg}$ body twice a week for 4 weeks. First phase of experiment contained of seven treatments such as (1) control, (2) DMH (40 $\mathrm{mg} / \mathrm{kg}$ body weight), (3) DMH with $\mathrm{Se}$ (4 mg/l orally), (4) $\mathrm{DMH}$ with Se-enriched yeast cell wall $(2000 \mu \mathrm{g} / \mathrm{ml}$ i.p.), (5) DMH with Se-enriched yeast cytoplasmic fraction $(2000 \mu \mathrm{g} / \mathrm{ml}$ i.p.), (6) DMH with yeast cell wall $(2000 \mu \mathrm{g} / \mathrm{ml} \mathrm{i.p}$.) and (7) DMH with yeast cytoplasmic fraction $(2000 \mu \mathrm{g} / \mathrm{ml}$ i.p. $)$ without enrichment.

\section{Sampling}

At the end of the study (40th week), sacrificed animals were authanized with chloroform, exsanguinated by heart puncture and colons and livers were removed. All sections were fixed in $\% 10$ formalin, and then 4-micrometer-sections were prepared for evaluation of tissue damage. Finally, enzymes such as alanin aminotransfrase (ALT), aspartate aminotransfrase (AST) and alkaline phosphatase (ALP) levels were measured by a commercial kit (Parsazmoon, Iran) and an autoanalyzer (BT 3000 Pluse, Italy) (16). To investigate the effect of $\mathrm{DMH}$ on colon, Bird and Good (2000) method was also used.

\section{Statistical analysis}

Data were analyzed by one-way analysis of variance (ANOVA), and Tukey test (a real difference stands to be called HSD). The results were considered statistically significant as $\mathrm{p}<0.05$. All statistical analyses were made by using SPSS 19 software package.

\section{Results}

Our histological findings demonstrated that injections of $\mathrm{DMH}$ damaged the liver by forming the inflammatory foci mostly in areas of exposure.
Increased inflammatory foci in the areas of exposure was not observed in the normal liver. Formation of inflammatory foci in the treated groups were declined compared to the cancer control (Figure 3). Also injection of $\mathrm{DMH}$ damaged the colon mucosa by forming ACF. Aberrant crypt foci (ACF), are described as preneoplastic lesions of colorectal carcinoma, which are useful intermediate biomarkers to assays effects of certain natural and synthetic compounds in chemically induced carcinogenesis. In our present study ACF were distinguished from normal crypts by their larger sizes, thicker epithelial lining, and larger pericryptal zone (Figure 4). The majority of ACF were present in the middle and distal parts of the colon. These findings support the view that ACF represent focal morphological alterations induced by DMH in the colonic mucosa and this may reflect the initiation step of carcinogenesis (17).

The results of this study showed that intraperitoneal injection of cell wall and cytoplasmic fractions of selenium-enriched $S$. cerevisiae in both experiment phases could alter the levels of three liver enzymes, including ALT, AST, and ALP, compared to the control. In the first phase, all treated groups except the yeast cell wall group decreased significantly the level of ALT $(p<0.05)$ than cancer control group. Treated with yeast cell wall could also reduce the level of this enzyme, but reduction was not significant statistically (Table 1).

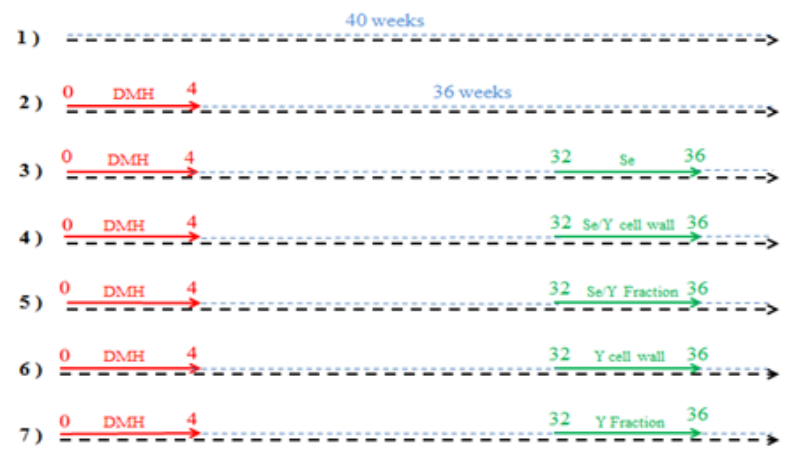

Figure 2. Experimental protocol in second phase. All animals except the control received 1, 2-dimethylhydrazine chloride 40 $\mathrm{mg} / \mathrm{kg}$ body twice a week for 4 weeks. Second phase of experiment contained of seven treatments such as (1) control, (2) DMH (40 $\mathrm{mg} / \mathrm{kg}$ body weight), (3) DMH with Se (4 mg/l orally), (4) DMH with Se-enriched yeast cell wall $(2000 \mu \mathrm{g} / \mathrm{ml}$ i.p.), (5) DMH with Se-enriched yeast cytoplasmic fraction $(2000 \mu \mathrm{g} / \mathrm{ml}$ i.p.), (6) DMH with yeast cell wall $(2000 \mu \mathrm{g} / \mathrm{ml}$ i.p.) and (7) DMH with yeast cytoplasmic fraction $(2000 \mu \mathrm{g} / \mathrm{ml}$ i.p.) without enrichment.

In the second phase, treatment with yeast cell wall, the cell wall of yeast enriched with selenium and selenium per se were significantly $(p<0.05)$ lowered the ALT level than cancer control. Although 
cytoplasmic fraction of yeast and selenium-enriched yeast cytoplasmic fraction decreased ALT level, this reduction was not significant statistically (Table 2 ). In the first phase, all treatments significantly $(\mathrm{p}<0.05)$ reduced AST level than the cancer control, but selenium-enriched cell wall of yeast created significantly great difference $(\mathrm{p}<0.05)$ compared to cancer control (Table 1). In the second phase, all treatments significantly $(\mathrm{p}<0.05)$ decreased AST level in comparison to cancer control ; moreover, selenium -enriched cell wall of yeast caused significantly great difference $(\mathrm{p}<0.05)$ compared to cancer control. Measuring the level of ALP in the first phase showed that treatment of enriched selenium yeast cell wall and cytoplasmic fraction could significantly $(p<0.05)$ reduce ALP level whereas there was no significant reduction in other treatments (Table 1). In the second phase, treatment with cell wall of yeast and cell wall of yeast enriched with selenium showed more significant decrease $(p<0.05)$ in ALP level than cancer control, but the other treatments had less significant reduction $(\mathrm{p}<0.05)$ in ALP level compared to cancer control.

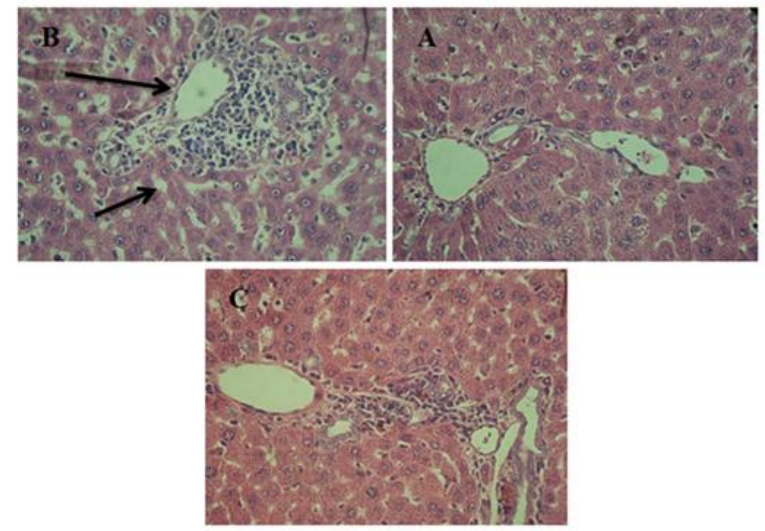

Figure 3. Liver tissue section, (A) liver of rat from healthy control group who had normal exposure space and lack of inflammatory foci, (B) liver of rat from cancer control group that: up arrow indicates inflammatory foci and down arrow indicates an increase in the exposure environment, (C) liver of rats treated with selenium-enriched yeast with the normal exposure space and inflammatory foci less than the control tumor (Hematoxylin and eosin staining, magnification $\times 400$ ).

\section{Discussion}

The results in this experiment showed that injection of DMH (for inducing colon carcinoma), increased the level of liver enzymes such as ALT, AST and ALP compared to the control group, and also our treatment of cell wall and cytoplasmic fraction of $S$. cerevisiae with selenium decreased the level of these enzymes compared to the DMH group. Alteration the level of liver enzymes is used to evaluate liver function and increase in level of these enzymes considered as hepatic lesions or hepatocytes damage
(10). Occurrence of hepatocytes necrosis induced release of these enzymes in blood circulation (11). Increased levels of AST indicate liver damage in some diseases, such as viral hepatitis cardiac infarction and muscle injuries while ALT is a liver specific parameter catalyzing the conversion of alanine to pyruvate and glutamate. So it is suitable for the detection of liver damages (11). Unlike ALT that is found mainly in the liver, AST is found in many other tissues such as heart, muscle, kidney, and brain. Almost all liver damages increase the levels of these two enzymes and increased level of serum ALP occurs in disorders of the biliary system too.

DMH is converted to the methyldiazuniom as active metabolite in the colon and liver by cytochrome p450 and this active metabolite causes O6-methyl-guanine mutation in DNA by binding to it (5). In addition, DMH causes disorders in antioxidant system in liver and also increases the activity of enzymes that metabolize toxin in liver and colon (5). Many studies have been evaluated liver damages that created by DMH injections. Also the results of this study showed that injection of DMH damaged the liver by forming the inflammatory foci and increasing them in areas of exposure. It also raised the activity of serum liver enzymes including ALT, AST, and ALP. This change in the level of serum liver enzymes may be pertinent to the toxic effect of DMH on liver.

Perse et al. (2011) found that intraperitoneal injection of Fullerenl nano particles $(100 \mathrm{mg} / \mathrm{ml})$ reduced activity of liver enzymes (ALT and AST) compared to the cancer group. They demonstrated antioxidant effects of nanoparticles on oxidative stress induced by dimethylhydrazine in the liver. In current study intraperitoneal injection of the cell wall and cytoplasmic fraction of selenium enriched yeast at $2000 \mu \mathrm{g} / \mathrm{ml}$ decreased the level of liver enzymes than the DMH control.

Kamaleeswari et al. (2006) proved that 30, 60 and 90 $\mathrm{mg} / \mathrm{kg}$ body weight of caraway inhibited carcinogenesis and development of ACF, and it also reduced fecal bile acids, sterols and ALT activity as well.

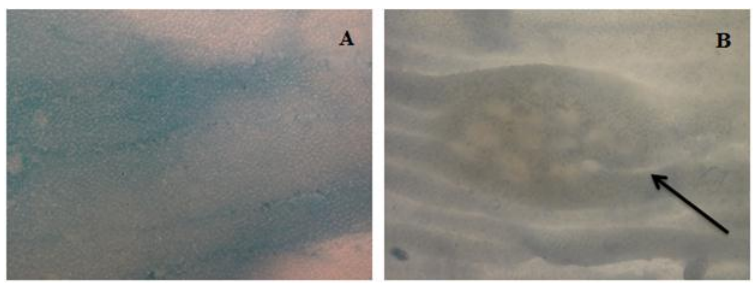

Figure 4. Methylene blue stained whole mount of colonic mucosa depicting a topographic view in control group (A) and a view of an $\mathrm{ACF}$ in cancer control group (B).

Jacobs et al. (1981 and 1983) stated that adding $4 \mathrm{ppm}$ selenium to the drinking water of mice before, 
during, and after injection of dimethylhydrazine reduced AST and ALP enzyme levels compared to dimethylhydrazine control groups. In this study, selenium in both treatments decreased ALP, AST and ALT enzyme levels compared to cancer control. Hart et al. (2009) demonstrated that probiotics could inhibit absorption of toxin and consequently could help to cure and prevent liver disease. Ziaii et al. (2009) also showed that the decrease in levels of serum liver enzymes in mice treated with probiotics strengthened the immune system and reduced stressinduced by liver disease.

In the present study, the effects of selenium and selenium-enriched/non-enriched $S$. cerevisiae cell wall and cytoplasmic fractions on liver enzymes were assessed and histological changes in the liver and colon cancers were examined as well. The findings were similar to the results of previous studies in which the levels of AST and ALP reduced compared to the dimethyl hydrazine control group. In cancer control, injection of DMH damaged the liver showing inflammatory cells infiltration in areas of exposure and raising the levels of serum liver enzymes including ALT, AST, and ALP.

According to these results, it is concluded that administration of cell wall and cytoplasmic fraction of Se-enriched $S$. cerevisiae can reduce the tissue changes in the rat liver created by DMH injection. However, many studies are needed to evaluate the exact mechanism of these effects.

\section{Acknowledgments}

The authors of the study do appreciate and thank to financial support from the Faculty of Science, Urmia University.

\section{References}

1. Hsueh-Chun W, Chia-Hung H, Jeng-Dong H, Mon-Yuan Y, Shing-Jung W, Chau-Jong W. Inhibitory effect of whole oat on aberrant crypt foci formation and colon tumor growth in ICR and BALB/c mice. J Cereal Sci. 2011; 53(1): 73-7.

2. Tukmechi A, Rahmati Andani HR, Manaffar R, Sheikhzadeh N. Dietaryadministrationofbeta-mercapto-ethanoltreated Saccharomyces cerevisiae enhanced the growth, innate immune response and disease resistance of the rainbow trout, Oncorhynchus mykiss. Fish Shellfish Immunol.2011;30(3):923-8.PMID: 21296672

3. Jacobs MM, Forst CF, Beams FA. Biochemical and clinical effects of selenium on dimethyl hydrazine induced colon cancer in rats. Cancer Res 1981; 41: 4458-65. PMID:7306970

4. Jacobs MM. Selenium inhibition of 1, 2-Dimethyl hydrazine induced colon carcinogenesis. Cancer Res. 1983; 43:1646-9. PMID: 6831412

5. Dadkhah A, Fatemi F. Effects of anti tomuric property of black cumin on induced colon cancer with dimethyl hydrazine in rat. New Find Lab Res. 2010; 1-32.

6. Kamaleeswari M, Deeptha K, Sengottuvelan M, Nalili N. Effect of dietary caraway (Carum carvi L.) on aberrant crypt foci development, fecal stroids, and intestinal alkaline phosphatase activities in 1, 2-dimethylhydrazine-induced colon carcinogenesis. Toxicol Appl Pharmacol. 2006; 214(3):290-6. PMID: 16483625

7. Hart AL, Kamm MA. Mechanism of action of probiotics. Recent advances. Inflamm Bowel Dis. 2009; 15(2):300-10. PMID: 18626975

8. Miezeliene A, Alencikiene G, Gruzauskas R, Barstys T. The effect of dietary selenium supplementation on meat quality of broiler chickens. Biotechnol Agron Soc Environ. 2011; 15(S1): 6169.

9. Boniadi F, Tukmechi A, Nejati V. Comparative study on the effect of obtained wall and cytoplasmic fraction from Saccharomyces cerevisiae and S. bulardii on K562 cell line. Pharma Sci. 2012; 1: 69-78.

10. Fatemi F, Allameh A, Dadkhah A, Forouzandeh M, Kazemnejad S, Sharifi R. Changes in hepatic cytosolic glutathione $\mathrm{S}$-transferase activity and expression of its class-P during prenatal and postnatal period in rats treated with aflatoxin B1. Arch Toxicol. 2006; 80(9):572-9. PMID: 16501953

11. Rahman MP. The use of high-selenium yeast to raise selenium status how does it measure up. British J Nutr. 2004; 92(4):557-3. PMID: 15522125

12. Wang Z, Zhang L, Tan T. High cell density fermentation of Saccharomyces cerevisiae GS2 for selenium-enriched yeast production. Korean J Chem Engin. 2010; 17 (6): 1836-40.

13. Yin H, Fan G, Gu Z. Optimization of culture parameters of selenium-enriched yeast (Saccharomyces cerevisiae) by response surface methodology (RSM). Food Scie Technol 2010; 43: 666-9.

14. Bradford MM. A rapid and sensitive method for the quantitation of microgram quantities of protein utilizing the principle of protein-dye binding. Anal Biochem. 1976; 72: 248-54. PMID: 942051

15. Bird RP, Good CK. The significance of aberrant crypt foci in understanding the pathogenesis of colon cancer. Toxicol Lett. 112113 (2000) 395-402. PMID: 10720758

16. Seyedi B, Heydari R, Tukmechi A. Assessment of the nutritional effects of Lactobacillus casei and Lactobacillus probiotics plus Raffinose on growth and liver enzymes in rats. rjms. Tums. 2012; 107: 20.

17. Karthik Kumar V, Venila S, Nalini N. Inhibitory effect of morin on DMH-induced biochemical changes and aberrant crypt foci formation in experimental colon carcinogenesis. Environ Toxicol Pharmacol. 2010; 29(1): 50-57.

18. Kumar VK, Vennila S, Nalini N. Inhibitory effect of morin on DMH-induced biochemical changes and aberrant crypt foci formation in experimental colon carcinogenesis. Environ Toxicol Pharmacol 2010; 29(1): 50-57. PMID: 21787582

19. Liong M. Roles of probiotics and prebiotics in colon cancer prevention: postulated mechanisms and In-vivo evidence. Int J Mol Sci. 2008; 9(5): 854-63. PMID: 19325789

20. Marteau PR, De Vrese M, Cellier CJ, Schrezenmeir J. Protection from gastrointestinal diseases with the use of probiotics. Amer J Clin Nutr. 2001; 73(2 Suppl):430S-436S. PMID: 11157353

21. Miezeliene A, Alencikiene G, Gruzauskas R, Barstys T. The 
effect of dietary selenium supplementation on meat quality of broiler chickens. Biotechnol Agron Soc Environ. 2011; 15 (S1): 61-9.

22. Perse M, Injac R, Djordjevic A, Strukelj B, Cerar A. Protective effect of Fullerenol nano particles on colon cancer development in dimethyl hydrazine rat model. Digest J Nano Bioss. 2011; 1535 43.

23. Shike M, Winamer SJ, Greenwald PH, Bolch A, Hill M, Swaroop SV. Primary prevention of colorectal cancer. Bull World Health Organ. 1998; 68(3): 377-85.

24. Stanton C, Gardiner G, Meehan H, Collins K, Fitzgerald G, Lynch PB, et al. Market potential for probiotics. Amer J Clin Nutr 2001; 48: 132-5. PMID: 11157361
25. Stein K, Borowicki A, Scharlau D, Schettler A, Scheu K, Obst $\mathrm{U}$, Glei M. Effect of symbiotic fermentation products on primary chemoprevention in human colon cell. J Nutr Biochem. 2012; 23: 777-84. PMID: 21840698

26. Ziaii H, Karimi A, Bashteni L, Naeimi pour H, Zinali A. Impact of alternative combinations of antibiotics on some biochemical parameters of blood serum humoral immune response of broilers. J Agricult Sci Natl Res. 2010; 2: 153-42. 